\title{
Deposit Spreads and the Welfare Cost of Inflation
}

\author{
Pablo Kurlat* \\ Stanford University
}

December 2018

\begin{abstract}
Since bank deposits and currency are substitutes and banks have monopoly power, higher nominal interest rates lead to higher deposit spreads. This raises the cost of transaction services, increases bank profits and attracts entry into the banking sector. Taking these effects into account, a one percentage point increase in inflation has a welfare cost of $0.086 \%$ of GDP, 6.9 times higher than traditional estimates.
\end{abstract}

Keywords: Inflation, bank deposits, money demand

JEL codes: E31, E41, G21, D43

*I am grateful to Adrien Auclert, William Barnett, Sebastian Di Tella, Javier Garcia Cicco, Ester Faia, Ryan Mattson, Daniel Paravisini and Isaac Sorkin for helpful comments. Ricardo de la O Flores provided outstanding research assistance. Correspondence: Department of Economics, Stanford University. 579 Serra Mall, Stanford, CA, 94305. Email: pkurlat@stanford.edu 
The welfare cost of inflation is a longstanding concern of monetary economics, and the recent debate about raising the inflation target lends it renewed relevance. One reason that inflation is costly is that, other things being equal, higher inflation induces households to reduce their money balances, forgoing some of the convenience of carrying money to conduct transactions. A standard method for measuring the magnitude of this cost, proposed by Bailey (1956) and pursued by Lucas (2000) and Ireland (2009) among others, is to measure the area under the money demand curve. This is valid as long as money does not pay interest and is costless to create. In this paper I propose and quantify a model that makes it possible to extend this calculation to the case where bank-created money pays interest, there are fixed costs to operating a bank, and the banking industry responds to changes in interest rates.

The model is a variant of Drechsler et al. (2017). Households value the transaction services of currency and several types of bank deposits, which are imperfect substitutes. The opportunity cost of holding currency is the nominal interest rate; the opportunity cost of holding a bank deposit is the deposit spread: the difference between the market interest rate and the deposit interest rate. Banks have a fixed cost of operating but zero marginal cost of issuing deposits, and have some degree of monopoly power to set deposit spreads. Under constant elasticity of substitution, equilibrium spreads depend positively and linearly on the nominal interest rate.

I assume that there is free entry into the banking industry. An increase in deposit spreads raises bank profits, attracting entry until profits are diluted back to equal fixed costs. The increase in the real amount of resources dedicated to fixed costs is part of the welfare cost of higher inflation.

I estimate the parameters of the model using using a detailed database on deposit rates. I first document, using time series variation, that the relationship between the interest rate and deposit rates is indeed positive and close to linear. I then estimate the elasticity of demand for deposits using geographic cross sectional variation in market shares of the largest banks. Together with data on monetary aggregates, this makes it possible to construct an aggregate measure of money and estimate its demand elasticity. Finally, I measure the elasticity of bank profits with respect to bank concentration using cross sectional variation in the exposure of local markets to bank mergers. Together, these estimates make it possible to quantify the model.

I use the model to compute the welfare cost of a permanent increase in the inflation rate by one percentage point (raising nominal interest rates from $2.5 \%$ to $3.5 \%$ ) and find it to be 
0.086\% of GDP, which is 6.9 times higher than one finds using the approach in Lucas (2000) and Ireland (2009). A factor of 1.9 results from constructing a monetary aggregate in the way the model suggests, while the rest of the difference comes from taking into account the resources dedicated to additional bank costs.

\section{The Model}

\subsection{The Environment}

The model is based on Drechsler et al. (2017). There is a representative household with preferences

$$
u(y, m)=y+\frac{\eta}{\eta-1} \beta^{\frac{1}{\eta}} m^{\frac{\eta-1}{\eta}}
$$

where $y$ is consumption and $m$ is transaction services from money holdings. The monetary aggregate $m$ is a nested CES aggregate of real currency $c$ and bank deposits $d$, with elasticity of substitution $\epsilon$ :

$$
m=\left[\alpha^{\frac{1}{\epsilon}} c^{\frac{\epsilon-1}{\epsilon}}+(1-\alpha)^{\frac{1}{\epsilon}} d^{\frac{\epsilon-1}{\epsilon}}\right]^{\frac{\epsilon}{\epsilon-1}}
$$

Deposits are a CES aggregate of deposits $d_{n}$ from $N$ different banks, with elasticity of substitution $\sigma$ :

$$
d=\left(\sum_{n=1}^{N} \mu_{n}^{\frac{1}{\sigma}} d_{n}^{\frac{\sigma-1}{\sigma}}\right)^{\frac{\sigma}{\sigma-1}}
$$

Deposits at bank $n$ are themselves a CES aggregate of $J$ different types of deposits $d_{j n}$, with elasticity of substitution $\epsilon_{d}$ :

$$
d_{n} \equiv\left[\sum_{j=1}^{J} \alpha_{j}^{\frac{1}{\epsilon_{d}}} d_{j n}^{\frac{\epsilon_{d}-1}{\epsilon_{d}}}\right]^{\frac{\epsilon_{d}}{\epsilon_{d}-1}}
$$

When I quantify the model, I set $J=2 ; d_{1 n}$ represents checking accounts and $d_{2 n}$ represents savings accounts at bank $n$, both of which provide some amount of transaction services. ${ }^{1}$ The nested structure embodies the assumption that bank customers purchase banking services in bundles and competition across banks takes place at the level of the bundle rather than at the level of the individual deposit type. ${ }^{2}$

\footnotetext{
${ }^{1} \mathrm{I}$ also re-do the calculations for $J=3$, where $d_{3 n}$ represents small time deposits.

${ }^{2}$ Amel and Starr-McCluer (2002) and Amel et al. (2008) report that about $73 \%$ and $60 \%$ of checking and savings deposit accounts respectively are held by households at their primary institution.
} 
The government sets a nominal interest rate $i$ and costlessly supplies as much currency $c$ as households demand. Deposits are supplied by banks; they have a fixed cost $\kappa$ of operating but can supply unlimited amounts of deposits at zero marginal cost. Since they have monopoly power over their particular variety of deposit, they have to decide what interest rate they will pay. Denote by $i_{j n}$ the interest rate paid by bank $n$ on deposits of type $j$ and let $s_{j n} \equiv i-i_{j n}$ be the deposit spread.

\subsection{The Household's Problem}

The household chooses its money holdings by maximizing (1) subject to the budget constraint

$$
y+\iota m \leq w
$$

where $w$ is the household's wealth (which is irrelevant thanks to quasilinear preferences) and $\iota$ is the minimized cost of holding one unit of the monetary aggregate $m$ :

$$
\begin{aligned}
\iota & \equiv \min _{c, d} i c+s d \quad \text { s.t. } \quad m=1 \\
& =\left(\alpha i^{1-\epsilon}+(1-\alpha) s^{1-\epsilon}\right)^{\frac{1}{1-\epsilon}}
\end{aligned}
$$

For currency, which pays zero nominal interest rate, the opportunity cost of holding it is the interest rate $i$. The opportunity cost of holding deposits is the composite spread $s$, which is an index of the deposit spreads charged by the $N$ banks:

$$
\begin{aligned}
s & \equiv \min _{d_{n}} s_{n} d_{n} \quad \text { s.t. } \quad d=1 \\
& =\left(\sum_{n=1}^{N} \mu_{n} s_{n}^{1-\sigma}\right)^{\frac{1}{1-\sigma}}
\end{aligned}
$$

The spread on deposits at bank $n$ is an index of the cost of holding the $J$ different types of deposits:

$$
\begin{aligned}
s_{n} & \equiv \min _{d_{j n}} \sum_{j=1}^{J} s_{j n} d_{j n} \quad \text { s.t. } \quad d_{n}=1 \\
& =\left(\sum_{j=1}^{J} \alpha_{j} s_{j n}^{1-\epsilon_{d}}\right)^{\frac{1}{1-\epsilon_{d}}}
\end{aligned}
$$


It's straightforward to show that the optimal amounts of money holdings, currency holdings, total composite deposits, composite deposits at bank $n$ and $j$-deposits at bank $n$ are, respectively:

$$
\begin{aligned}
m & =\beta \iota^{-\eta} \\
c & =\alpha m\left(\frac{i}{\iota}\right)^{-\epsilon} \\
d & =(1-\alpha) m\left(\frac{s}{\iota}\right)^{-\epsilon} \\
d_{n} & =\mu_{n} d\left(\frac{s_{n}}{s}\right)^{-\sigma} \\
d_{j n} & =\alpha_{j} d_{n}\left(\frac{s_{j n}}{s_{n}}\right)^{-\epsilon_{d}}
\end{aligned}
$$

\subsection{The Bank's Problem}

Bank $n$ sets interest rates (or, equivalently, spreads) on the $J$ different types of deposits to solve:

$$
\max _{\left\{s_{j n}, d_{j n}\right\}_{j=1}^{J}} \sum_{j=1}^{J} s_{j n} d_{j n}-\kappa
$$

subject to (5)-(12). Using (7), (11) and (12), the objective function reduces to:

$$
\sum_{j=1}^{J} s_{j n} d_{j n}=s_{n} d_{n}-\kappa
$$

Since households choose deposit services in bundles, it is the price of the bundle $s_{n}$ that matters for bank profits. The first order condition for optimally setting the spread $s_{n}$ is:

$$
1=-\frac{\partial \log d_{n}}{\partial \log s_{n}}
$$

Since the marginal cost is zero, banks set spreads to maximize total spread income. They do so by looking for the point on the demand curve where the elasticity of their individual demand is minus one. Using (5)-(12), the elasticity of demand faced by bank $n$ is:

$$
\frac{\partial \log d_{n}}{\partial \log s_{n}}=\left[-\epsilon+(1-\alpha)(\epsilon-\eta)\left(\frac{s}{\iota}\right)^{1-\epsilon}+\sigma\right] \mu_{n}\left(\frac{s_{n}}{s}\right)^{1-\sigma}-\sigma
$$




\subsection{Spreads}

Define $\eta_{d}$ as the elasticity of the total demand for deposits with respect spreads $s$ :

$$
\eta_{d} \equiv-\frac{\partial \log d}{\partial \log s}
$$

Using (8)-(11):

$$
\eta_{d}=\epsilon-(1-\alpha)(\epsilon-\eta)\left(\frac{s}{\iota}\right)^{1-\epsilon}
$$

Replacing (16) and (14) in the first order condition for spreads (13):

$$
1=\sigma+\left[\eta_{d}-\sigma\right] \mu_{n}\left(\frac{s_{n}}{s}\right)^{1-\sigma}
$$

In an equilibrium with symmetric banks, with $\mu_{n}=\frac{1}{N}$ and $\frac{s_{n}}{s}=1$, the first order condition (17) reduces to:

$$
\eta_{d}=1-(\sigma-1)(N-1)
$$

Equation (18), also found in Drechsler et al. (2017), has the following interpretation. If a bank was a pure monopoly $N=1$, it would face the total demand for deposits, so it would set spreads at the point where the elasticity of total deposit demand is equal to minus one. As the level of competition increases (either because there are more banks, or they are closer substitutes to each other), demand for an individual bank's deposits becomes more elastic than total demand. Since individual demand elasticity must be equal to minus one, this means that the equilibrium spread $s$ must be at a less elastic point of the market demand curve.

Rearranging (16), equilibrium spreads must satisfy

$$
s=\left(\frac{\epsilon-\eta_{d}}{\epsilon-\eta} \frac{1}{1-\alpha}\right)^{\frac{1}{1-\epsilon}} \iota
$$

and, using (5), this implies that

$$
s=\left(\frac{\epsilon-\eta_{d}}{\eta_{d}-\eta} \frac{\alpha}{1-\alpha}\right)^{\frac{1}{1-\epsilon}} i
$$

Therefore spreads are a linear function of the interest rate $i$. The substitutability of currency 
and deposits means that the opportunity cost of currency acts as an anchor for deposit spreads. Note that this relies on banks actively choosing to exercise their monopoly power by adjusting the price, and therefore the quantity, of deposits in response to the interest rate. Di Tella and Kurlat (2017) study a similar model but where the supply of deposits is fixed at a multiple of bank net worth. In that model, as the interest rate rises, households substitute away from currency towards deposits, which leads to higher spreads and a fall in the quantity of currency. However, this effect weakens as the interest rate rises because there is less currency to substitute away from. Therefore, unless the currency-to-deposit ratio at low interest rates is very high, spreads rapidly become flat at higher interest rates. Here, instead, banks actively adjust spreads to keep $\frac{s}{i}$ constant. Using (9) and (10), this implies a constant currency-to-deposit ratio.

Replacing (19) in (5), the overall cost of transaction services is: ${ }^{3}$

$$
\iota=\left(\alpha \frac{\epsilon-\eta}{\eta_{d}-\eta}\right)^{\frac{1}{1-\epsilon}} i
$$

\subsection{Bank Profits and Entry}

Total bank profits (gross of fixed costs) are:

$$
\pi=s d
$$

Replacing (8), (10), (19) and (20):

$$
\pi=\beta \alpha^{\frac{1-\eta}{1-\epsilon}}\left(\frac{\epsilon-\eta}{\eta_{d}-\eta}\right)^{\frac{1-\eta}{1-\epsilon}}\left(\frac{\epsilon-\eta_{d}}{\epsilon-\eta}\right) i^{1-\eta}
$$

\footnotetext{
${ }^{3}$ Spreads for individual types of deposits $s_{j}$ are indeterminate because only the price of the bundle matters, for both banks and households, but it's easy to extend the model to pin them down. Suppose a fraction of households only use checking accounts while the rest use both checking and savings accounts. The composite deposit for the checking-only group is just $d_{1 n}$ and its elasticity of substitution across banks is denoted $\sigma_{1}$. The same reasoning that leads to (19) implies that the equilibrium spread faced by this group is

$$
s_{1}=\left(\frac{\epsilon-\eta_{1}}{\eta_{1}-\eta} \frac{\alpha}{1-\alpha}\right)^{\frac{1}{1-\epsilon}} i
$$

with

$$
\eta_{1}=1-\left(\sigma_{1}-1\right)(N-1)
$$

Banks set the checking spread $s_{1}$ at the level that would result if all households only had checking accounts and set the spread on savings accounts $s_{2}$ so that the composite spread $s$ satisfies (19). Since the spreads on individual types of deposits do not play a role in the welfare calculations below, I conduct the analysis at the level of the composite spread $s$.
} 
Other things being equal, if $\eta<1$ then bank profits are increasing in the nominal interest rate. Higher interest rates are associated with higher spreads, but also lower deposit holdings. If the elasticity of money demand is less than 1 , then the first effect dominates and profits are increasing.

I assume that there's free entry into the banking sector. An entering bank automatically obtains a market share $\frac{1}{N}$ (the fixed cost includes whatever advertising or setup costs are involved in attaining this market share). Ignoring integer constraints, the free entry condition is

$$
\frac{\pi}{N}=\kappa
$$

For the welfare calculation, it will be necessary to compute the elasticity of entry with respect to the interest rate. Using the implicit function theorem, the free entry condition (23) implies that the elasticity of the number of banks with respect to the interest rate is:

$$
\frac{\partial \log N}{\partial \log i}=\frac{\frac{\partial \log \pi}{\partial \log i}}{1-\frac{\partial \log \pi}{\partial \log N}}
$$

Equation (22) implies that

$$
\frac{\partial \log \pi}{\partial \log i}=(1-\eta)
$$

and equation (21) and definition (15) imply that

$$
\frac{\partial \log \pi}{\partial \log N}=\left(1-\eta_{d}\right) \frac{\partial \log s}{\partial \log N}
$$

Therefore:

$$
\frac{\partial \log N}{\partial \log i}=\frac{1-\eta}{1-\left(1-\eta_{d}\right) \frac{\partial \log s}{\partial \log N}}
$$

Entry will respond strongly to interest rates if (i) $\eta$ is low, because an inelastic money demand means that profits respond strongly to interest rates, (ii) the absolute value of $\frac{\partial \log s}{\partial \log N}$ is low, because this means that entry does not rapidly compete away total profits by lowering spreads, or (iii) the elasticity of demand for deposits is high, because this means that if entry does lower spreads, banks partly make up for it with higher volume. Taken literally, the model has implications for the value of $\frac{\partial \log s}{\partial \log N}$ but they are not robust to different ways of microfounding the source of banks' monopoly power. For instance, Drechsler et al. (2017) show that the model is isomorphic to one where, instead of just product differentiation, the source of market power is that a fraction of customers are stuck with one bank. For this 
reason, I will leave $\frac{\partial \log s}{\partial \log N}$ as an additional parameter to be estimated.

\subsection{Welfare}

The main exercise is to calculate the impact on welfare of an increase in the rate of inflation, which I assume translates one for one into an increase in the nominal interest rate. Welfare is given by:

$$
u=w-N \kappa+\frac{\eta}{\eta-1} \beta^{\frac{1}{\eta}} m^{\frac{\eta-1}{\eta}}
$$

I assume that bank profits and seignorage revenue are rebated back to the household. Therefore the representative household consumes its wealth minus what is spent on the fixed costs of banks, and also enjoys the transaction services provided by money. Importantly, I assume that banks' fixed costs involve spending real resources. If instead they represented some sort of fee that is also rebated back to the household, then they should not be subtracted from $(25)$.

The welfare effect of an increase in the nominal interest rate, expressed as a percentage of the monetary aggregate $m$ is:

$$
\frac{d u}{d i} \frac{1}{m}=\underbrace{\beta^{\frac{1}{\eta}} m^{-\frac{1+\eta}{\eta}} \frac{d m}{d i}}_{\text {change in transaction services }}-\underbrace{\frac{1}{m} \frac{d(N \kappa)}{d i}}_{\text {change in fixed costs }}
$$

Take the first term in (26) first. Using (5), (8), (19) and (24), the change in the value of transaction services is: ${ }^{4}$

$$
\begin{aligned}
\beta^{\frac{1}{\eta}} m^{-\frac{1+\eta}{\eta}} \frac{d m}{d i} & =-\eta \frac{d \iota}{d i} \\
& =-\eta\left[\frac{\partial \iota}{\partial i}+\frac{\partial \iota}{\partial N} \frac{\partial N}{\partial i}\right] \\
& =-\eta\left(\alpha \frac{\epsilon-\eta}{\eta_{d}-\eta}\right)^{\frac{1}{1-\epsilon}}\left[1+\frac{\epsilon-\eta_{d}}{\epsilon-\eta} \frac{(1-\eta)}{\left(\frac{\partial \log s}{\partial \log N}\right)^{-1}-\left(1-\eta_{d}\right)}\right]
\end{aligned}
$$

\footnotetext{
${ }^{4}$ The functional form (3) with $\mu_{n}=\frac{1}{N}$ mechanically implies that as banks enter, households re-weight their preferences over deposits at different banks and there is no gain from variety in the term $\frac{\partial \iota}{\partial N}$. The alternative proposed by Drechsler et al. (2017) where the source of market power is captive consumers as opposed to product differentiation also has no direct gains from variety. If preferences did have a taste for variety, then this would be an additional channel (in addition to reduced market power), whereby entry lowers the effective cost of transaction services.
} 
Now compute the second term in (26). Using (8), (22), (23) and (24), the change in fixed costs is:

$$
\frac{d(N \kappa)}{d i} \frac{1}{m}=\left(\alpha \frac{\epsilon-\eta}{\eta_{d}-\eta}\right)^{\frac{1}{1-\epsilon}}\left(\frac{\epsilon-\eta_{d}}{\epsilon-\eta}\right) \frac{1-\eta}{1-\left(1-\eta_{d}\right) \frac{\partial \log s}{\partial \log N}}
$$

Replacing (27) and (28) into (26) and rearranging:

$$
\frac{d u}{d i} \frac{1}{m}=-\left(\alpha \frac{\epsilon-\eta}{\eta_{d}-\eta}\right)^{\frac{1}{1-\epsilon}}\left[\eta+\left(\frac{\epsilon-\eta_{d}}{\epsilon-\eta}\right) \frac{1-\eta}{1-\left(1-\eta_{d}\right) \frac{\partial \log s}{\partial \log N}}\left(\eta \frac{\partial \log s}{\partial \log N}+1\right)\right]
$$

For the case where there are no deposits $(\alpha=1)$, equation (29) reduces to the standard expression:

$$
\frac{d u}{d i} \frac{1}{m}=-\eta
$$

that relates the welfare cost of inflation to the elasticity of money demand. For the general case, the formula takes into account three additional forces.

First, as set out by equation (20), the slope of the cost of transaction services with respect to the interest rate need not equal one. Hence the factor $\left(\alpha \frac{\epsilon-\eta}{\eta_{d}-\eta}\right)^{\frac{1}{1-\epsilon}}$, which translates increases in interest rates into increases in the cost of transaction services.

Second, other things being equal, higher rates make banks more profitable, which induces entry, and real resources are dedicated to the fixed costs of the entering banks. This is captured by the terms in equation (28). The hypothesis that higher inflation leads to a larger banking sector has been studied before. English (1999) documents a positive crosscountry correlation between the share of financial sector value added in GDP and the rate of inflation. Yoshino (1993) shows country-by-country time-series evidence in the same direction. Bresciani Turroni (1937), Wicker (1986), Marom (1998), Kleiman (1989) and Aiyagari et al. (1998) also document this correlation, focusing on episodes of very high inflation. Dotsey and Ireland (1996) study a quantitative model where this effect is present. ${ }^{5}$

Third, entry affects spreads by increasing competition, partly offsetting the increase in the opportunity cost of money. This is reflected in the second term inside the brackets in equation (27), which results from computing $\frac{\partial \iota}{\partial N} \frac{\partial N}{\partial i}$.

The traditional calculation based on equation (30) concludes that a relatively inelastic

\footnotetext{
${ }^{5}$ Note that the correlation between inflation and the size of the banking sector will be present if one measures the size of the banking sector by its value added or by total operating costs but not if one measures it by the volume of deposits.
} 
money demand implies a low welfare cost of inflation, because it means that the area under the demand curve is small. Equation (29) implies an effect in the opposite direction. An inelastic money demand means that bank profits respond strongly to higher interest rates, inducing entry and the associated fixed costs.

\section{Measurement}

\section{$2.1 \quad$ Data}

The first source of data is the monetary aggregates compiled by the Federal Reserve, which I use to construct monthly time series of $c$ and $d_{j} . c$ is the stock of currency in circulation. $d_{1}$ is M1 adjusted for retail sweeps minus currency. ${ }^{6} d_{2}$ is the savings deposits component of M2 minus the difference between M1 adjusted and unadjusted for retail sweeps. All the monetary aggregates are scaled by dividing by annualized nominal GDP (from NIPA) for the corresponding quarter. When I re-do the calculations for $J=3$, I let $d_{3}$ be the small time deposit component of M2. In addition, for purposes of comparison, I look at Monetary Services Index (MSI) aggregate computed by the Federal Reserve of St. Louis and the Divisia M2, M3 and M4 indices published by the Center for Financial Stability and their corresponding user costs.

The second source of data is deposit data from the Federal Deposit Insurance Corporation. The FDIC reports a total dollar amount of deposits for each bank branch at an annual frequency. I aggregate this data up to the county level to construct an annual panel of countylevel deposits. Unfortunately, the FDIC just reports total deposits, without distinguishing between different types of deposits.

The next source of data is on deposit interest rates. The firm RateWatch conducts a weekly survey of interest rates paid on various types of deposits of about 16,000 bank branches, representing approximately $25 \%$ of total deposits in the US. I use this data to construct both aggregate time series and a county-level panel on deposit spreads spanning from December 1997 to December 2017. I aggregate to either the county or the national level by taking total-deposit-weighted averages across bank branches (where the weights are constructed using the FDIC data). I do this separately for three types of deposits. $s_{1}$ is constructed using rates on "Interest Checking Accounts with no lower limit" and $s_{2}$ using

\footnotetext{
${ }^{6}$ Retail sweeps are like checking accounts from the point of view of the bank customer but are classified as savings accounts and not included in M1; the adjusted series adds them back in. See Anderson and Jones (2011) for details.
} 
rates on "Money Market Accounts with $\$ 25,000$ lower limit". When I set $J=3$, I construct $s_{3}$ using rates on " 12 -month Certificates of Deposit with $\$ 10,000$ lower limit". These are the most common types of checking, savings and time deposit accounts, offered by $95.9 \%, 97.2 \%$ and $99.5 \%$ of all bank branches respectively.

As discussed by Anderson and Jones (2011), the empirical counterpart of the model concept of a market interest rate is not entirely clear. Conceptually, this corresponds to the interest rate on a safe asset that does not provide any transaction services. In practice, most safe assets are at least somewhat useful for conducting some types of transactions. As a baseline, I construct a time series of $i$ as the maximum of: the effective federal funds rate, the 3-month LIBOR rate, the yield on 3-month AA + commercial paper, 3-month Broad GC repo rates, 3-month banker's acceptance rates and the median rate (across all bank branches) on 3 -month time deposits of $100 \mathrm{~K}+$ dollars. I then define spreads as the difference between the deposit rate and this benchmark rate.

Finally, in the estimation of the elasticity of spreads with respect to entry, I make use of the Commercial Bank Database of the Federal Reserve, which contains data on bank mergers.

\subsection{Parameters and Moments}

Expression (29) depends on five numbers: $\frac{\partial \log s}{\partial \log N}, \epsilon, \eta, \alpha$ and $\eta_{d}$. I measure $\frac{\partial \log s}{\partial \log N} \operatorname{directly}$ using cross-sectional data. I set the remaining four parameter values to jointly match the elasticity of money demand, the elasticity of deposit demand, the slope of deposit spreads with respect to interest rates and the currency-to-deposit ratio. Matching these moments is a fixed point problem, which can be solved in a number of ways. I do so by iterating on the following steps, starting from conjectured values for $\epsilon, \eta, \alpha, \eta_{d}$ and the elasticity of substitution across deposit types $\epsilon_{d}$.

The first step is to compute weights $\left\{\alpha_{j}\right\}_{j=1}^{J}$ on the $j$ deposit types and the slope of the composite spread $s$ with respect to $i$, which I denote by $\gamma$. I use the $J$ time series of spreads on different deposit types to estimate linear regressions of $s_{j t}$ on $i_{t}$. Denote the estimated slopes by $\gamma_{j}$. Using (7), $\gamma$ aggregates the individual slopes according to:

$$
\gamma=\left(\sum_{j=1}^{J} \alpha_{j} \gamma_{j}^{1-\epsilon_{d}}\right)^{\frac{1}{1-\epsilon_{d}}}
$$


Using (9), (10), (12) and symmetry across banks, the currency-to- $j$-deposit ratio is given by:

$$
\frac{c}{d_{j}}=\frac{1}{\alpha_{j}} \frac{\alpha}{1-\alpha}\left(\gamma_{j}\right)^{\epsilon_{d}} \gamma^{\epsilon-\epsilon_{d}}
$$

Using the conjectured values of $\epsilon, \alpha$ and $\epsilon_{d}$, and empirical moments $\gamma_{j}$ and $\frac{c}{d_{j}}$, I obtain values for $\left\{\alpha_{j}\right\}_{j=1}^{J}$ and $\gamma$ by solving equations (31) and (32).

The second step is to compute the currency-to-composite-deposit ratio. Equation (4) implies that it can be constructed from the individual currency-to- $j$-deposit ratios according to:

$$
\frac{c}{d}=\left(\sum_{j=1}^{J} \alpha_{j}^{\frac{1}{\epsilon_{d}}}\left(\frac{c}{d_{j}}\right)^{\frac{1-\epsilon_{d}}{\epsilon_{d}}}\right)^{\frac{\epsilon_{d}}{1-\epsilon_{d}}}
$$

The third step is to update the conjectured values of $\alpha$ and $\epsilon$. Using equations (8), (9) and (19), the model predicts that the currency-to-composite deposit ratio should be equal to:

$$
\frac{c}{d}=\frac{\alpha}{1-\alpha}\left(\frac{\epsilon-\eta_{d}}{\eta_{d}-\eta} \frac{\alpha}{1-\alpha}\right)^{\frac{\epsilon}{1-\epsilon}}
$$

Moreover, (19) implies that:

$$
\gamma=\left(\frac{\epsilon-\eta_{d}}{\eta_{d}-\eta} \frac{\alpha}{1-\alpha}\right)^{\frac{1}{1-\epsilon}}
$$

Equations (34) and (33) can be solved for $\epsilon$ and $\alpha$ in terms of empirical moments $\gamma$ and $\frac{c}{d}$ and parameters $\eta$ and $\eta_{d}$ :

$$
\begin{aligned}
\epsilon & =\left(\eta_{d}-\eta\right) \frac{\gamma}{c / d}+\eta_{d} \\
\alpha & =\frac{c / d}{\gamma^{\epsilon}+c / d}
\end{aligned}
$$

Equation (35) has the following interpretation. By (16), the elasticity of deposit demand is a weighted average of the elasticity of money demand $\eta$ and the elasticity of substitution between currency and deposits $\epsilon$. Therefore if I measure the elasticities of money and deposit demand I can reconstruct what elasticity of substitution rationalizes them. If the demand for deposits is highly elastic while the money demand is not, I will infer that what makes deposit demand elastic is substitution with currency, and find a high value of $\epsilon$. Equation (36) implies, unsurprisingly, that I will infer a high weight of currency in the money aggregate 
if the observed currency-to-deposit ratio is high.

The fourth step is to update the conjectured value of $\eta$. Using the updated values of $\alpha$ and $\epsilon$, I can construct a time series of $m_{t}$ using (2) and the subcomponents of monetary aggregates, and use it to estimate a money demand equation. Equation (8) implies that if I regress $\log m_{t}$ on $\log i_{t}$, the regression coefficient should be equal to $-\eta$.

The fifth and final step is to update the conjectured value of $\eta_{d}$. I use equation (7) and the estimated $\alpha_{j}$ to construct data on composite-deposit spreads. Then I use cross-sectional variation in spreads to estimate the elasticity of deposit demand with respect to spreads. By definition, this provides an estimate of $\eta_{d}$.

By iterating on these steps until convergence, I obtain values of $\epsilon, \alpha, \eta$ and $\eta_{d}$ for any conjectured value of $\epsilon_{d}$. The elasticity of inter-deposit substitution $\epsilon_{d}$ is harder to measure because I don't have the detailed cross-sectional quantity data by type of deposit that would allow estimation by the same procedure used to estimate currency-deposit substitution. I therefore show results for different values of $\epsilon_{d}$, taking $\epsilon_{d}=1$ as a baseline.

\subsection{Empirical Results}

Figure 1 shows scatterplots of spreads on checking accounts and savings accounts against nominal interest rates. Both figures show a strong positive association between spreads and interest rates. ${ }^{7}$

Part of this association could be simply due to a form of stickiness. Although the theoretically relevant price for the deposit is the spread, prices for deposits are typically quoted in terms of the interest rate rather than the spread. A large empirical literature (Hannan and Berger 1991, Neumark and Sharpe 1992, Driscoll and Judson 2013, Craig and Dinger 2014, Yankov 2014) has documented that deposit rates take some time to react to changes in interest rates, which implies that spreads over-react in the short run. The model has nothing to say about these short-run dynamics, so I attempt to estimate the relationship between spreads and interest rates that remains after spreads have had time to adjust. ${ }^{8}$ Suppose that stickiness takes the form:

$$
i_{j t}=\lambda i_{j, t-1}+(1-\lambda)\left(1-\gamma_{j}\right) i_{t}
$$

\footnotetext{
${ }^{7}$ This is true in other countries as well. See Appendix A for some international evidence.

${ }^{8}$ In terms of mapping to the model, I assume that the data corresponds to equilibria of the model with fixed parameter values and different interest rates. In particular, I assume that interest rate changes are perceived as temporary and bank entry only responds to permanent changes, so all the data comes from a model with fixed $N$.
} 

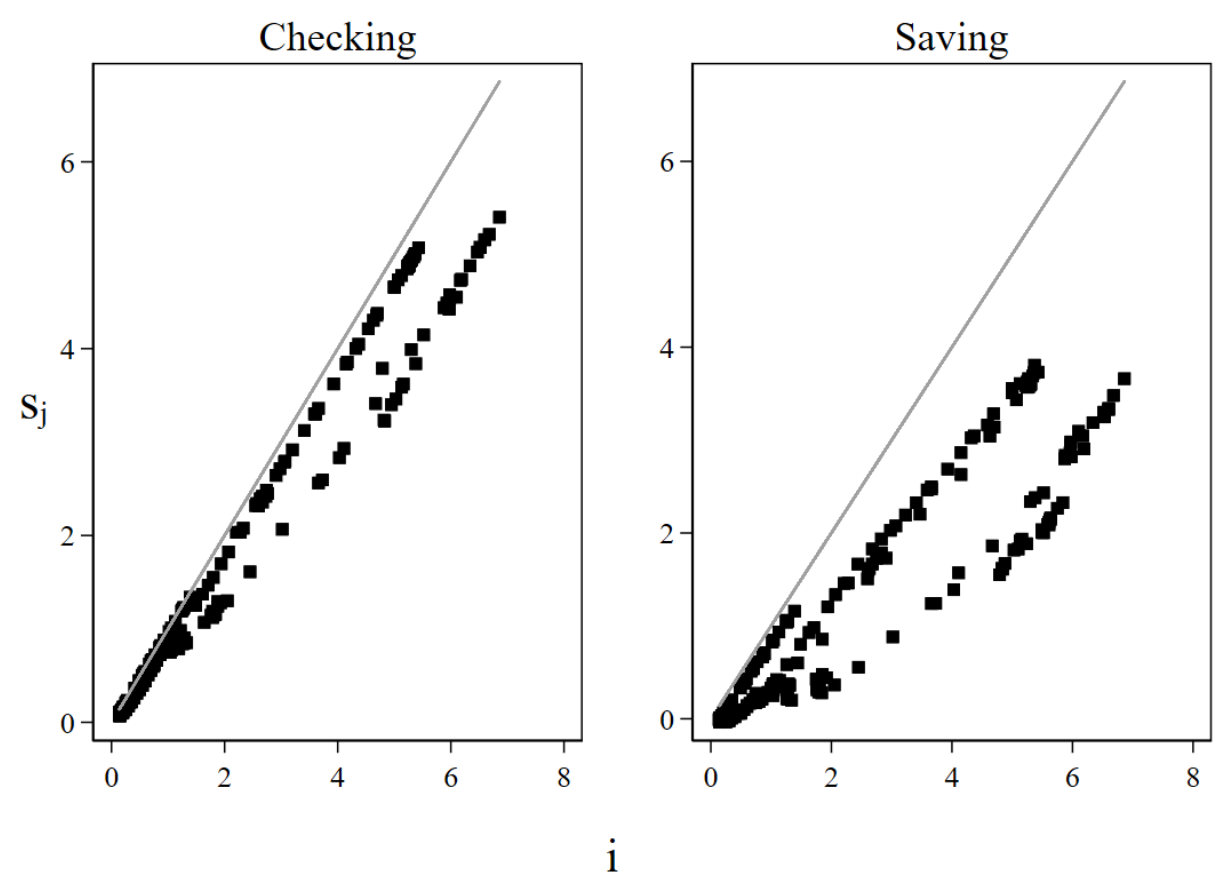

Figure 1: Spreads and interest rates

Expression (37) says that banks set rates on $j$-type deposits as a weighted average of their target rate $\left(1-\gamma_{j}\right) i_{t}$ and the rate they were offering the previous period. $\lambda=1$ would represent completely sticky rates and $\lambda=0$ immediate adjustment. Using $s_{j t}=i_{t}-i_{j t}$, this implies:

$$
s_{j t}=\left(1-(1-\lambda)\left(1-\gamma_{j}\right)\right) i_{t}-\lambda\left(i_{t-1}-s_{j, t-1}\right)
$$

In order to estimate $\gamma_{j}$, I estimate, for each $j$ :

$$
s_{j t}=a_{0 j}+a_{1 j} i_{t}+a_{2 j}\left(i_{t-1}-s_{j, t-1}\right)+v_{j t}
$$

and then set

$$
\gamma_{j}=1-\frac{1-a_{1 j}}{1+a_{2 j}}
$$

The model implies that $a_{0}$ should be equal to zero, so I also estimate versions that impose $a_{0}=0$. The results are shown on Table 1 . Columns 1 and 4 (for checking and savings respectively) correspond to the specification that does not impose $a_{0}=0$. The constant terms are very small, and not statistically different from zero, consistent with spreads being a linear function of $i$. Columns 2 and 5 impose $a_{0}=0$, which makes very little difference; 
columns 3 and 6 also impose $a_{2}=0$, equivalent to assuming no stickiness. Even though deposit rates are estimated to be quite sticky, taking stickiness into account does not change the estimated slopes very much. The slopes of spreads with respect to interest rates are estimated to be $\gamma_{1}=0.85$ for checking and $\gamma_{2}=0.57$ for savings. Using formula (31), the benchmark $\epsilon_{d}=1$ and the estimated values of $\alpha_{j}$, which are $\alpha_{1}=0.73$ and $\alpha_{2}=0.27$, this implies that the slope of composite deposits is $\gamma=0.76 .^{9}$

\begin{tabular}{|c|c|c|c|c|c|c|}
\hline & \multicolumn{3}{|c|}{$s_{1 t}$} & \multicolumn{3}{|c|}{$s_{2 t}$} \\
\hline & (1) & $(2)$ & $(3)$ & (4) & $(5)$ & (6) \\
\hline Constant & $\begin{array}{c}0.005 \\
(0.004)\end{array}$ & & & $\begin{array}{c}0.010 \\
(0.004)\end{array}$ & & \\
\hline$i_{t}$ & $\begin{array}{c}0.995 \\
(0.002)\end{array}$ & $\begin{array}{c}0.996 \\
(0.002)\end{array}$ & $\begin{array}{c}0.826 \\
(0.006)\end{array}$ & $\begin{array}{c}0.975 \\
(0.003)\end{array}$ & $\begin{array}{c}0.977 \\
(0.003)\end{array}$ & $\begin{array}{c}0.518 \\
(0.009)\end{array}$ \\
\hline$i_{j, t-1}$ & $\begin{array}{l}-0.973 \\
(0.011)\end{array}$ & $\begin{array}{c}-0.973 \\
(0.010)\end{array}$ & & $\begin{array}{l}-0.947 \\
(0.006)\end{array}$ & $\begin{array}{l}-0.946 \\
(0.006)\end{array}$ & \\
\hline Observations & 226 & 226 & 227 & 240 & 240 & 241 \\
\hline Implicit $\gamma_{j}$ & & 0.849 & & & 0.570 & \\
\hline
\end{tabular}

Table 1: Slope of spreads with respect to interest rates

Figure 2 shows scatterplots of the ratio of currency to deposit holdings against the nominal interest rate, for checking deposits, savings deposits and composite deposits $d$ (constructed using equation (4)). The model implies that these ratios should be constant. Even though they are not exactly constant, neither currency-to-checking nor currency-tosavings ratios show a strong correlation with interest rates, and neither does the currencyto-composite deposits ratio, justifying the approximation that $\frac{c}{d}$ is constant. The average value of $\frac{c}{d}$ is 0.22 .

Figure 3 shows scatterplots of the monetary aggregates (expressed as a fraction of GDP) against the nominal interest rate. The overall aggregate $m$ is constructed using equation (2) and the estimated $\alpha$ and $\epsilon$. The solid line is the best fit of a log-log regression, which is a relatively good fit, especially for the monetary aggregate $m$.

If the ratios between the monetary aggregates were exactly constant as predicted by the

\footnotetext{
${ }^{9}$ Banks charge for deposits in the form of fees in addition to spreads. Fees are negatively correlated with interest rates, so it's possible that this slope is somewhat overstated. See Appendix B for details.
} 

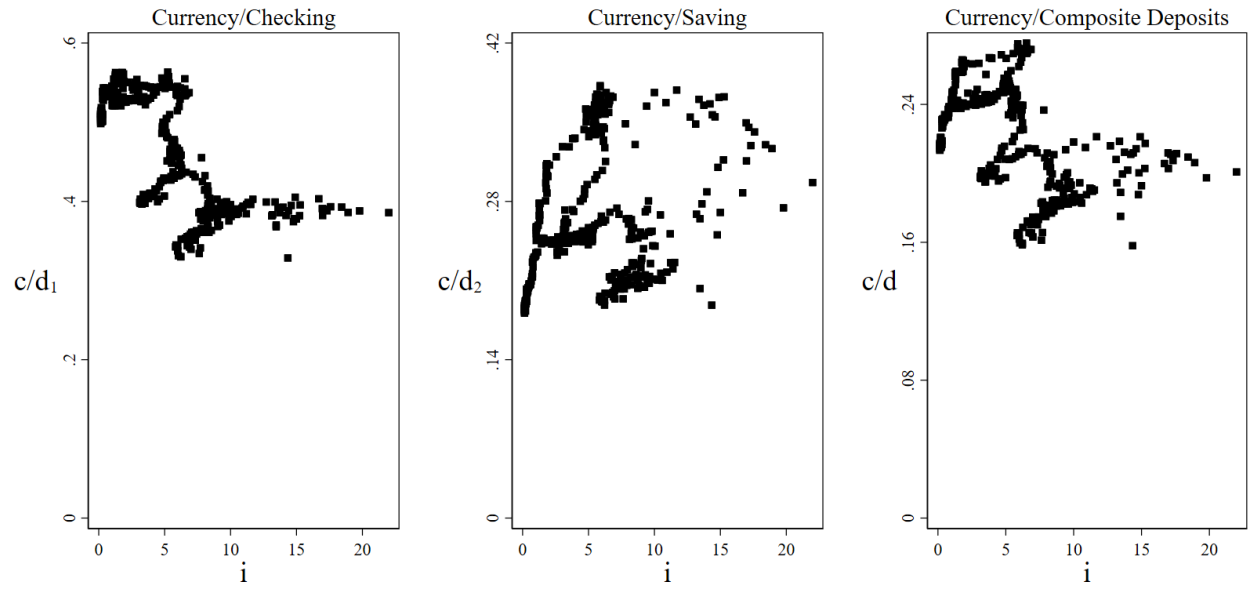

Figure 2: Currency to deposit ratios

model, the one could use any one of them to estimate a demand elasticity. I estimate:

$$
\log m_{t}=a_{0}-\eta \log i_{t}+v_{t}
$$

for each of the monetary aggregates. For comparison, I include conventionally-defined M1 (adjusted for retail sweeps) and the MSI among the monetary aggregates. The results are shown on Table 2. I take as the baseline value the estimate for the composite monetary aggregate $m$, which is $\eta=0.11$.

\begin{tabular}{lcccccc}
\hline \hline & $(1)$ & $(2)$ & $(3)$ & $(4)$ & $(5)$ & $(6)$ \\
& $\log c$ & $\log d_{1}$ & $\log d_{2}$ & $\log m$ & $\log M 1$ & $\log$ MSI \\
\hline Constant & -3.49 & -2.45 & -2.43 & -1.69 & -2.15 & -0.62 \\
& $(0.02)$ & $(0.01)$ & $(0.03)$ & $(0.01)$ & $(0.01)$ & $(0.02)$ \\
$\log i$ & -0.13 & -0.05 & -0.22 & -0.11 & -0.08 & -0.03 \\
& $(0.00)$ & $(0.00)$ & $(0.01)$ & $(0.00)$ & $(0.00)$ & $(0.00)$ \\
\hline Observations & 408 & 408 & 408 & 408 & 408 & 408 \\
\hline \hline
\end{tabular}

Monthly data from Jan 1980 to Dec 2013. Newey-West standard errors in parentheses

Table 2: Money demand elasticity

In order to estimate the elasticity of demand for deposits, I exploit cross-sectional variation in deposit spreads. I assume that households obtain banking services exclusively in their own county, so that each county represents a separate experiment of the model. ${ }^{10}$ Let

\footnotetext{
${ }^{10}$ Amel et al. (2008) report that over $94 \%$ of households have their main checking account at a branch
} 

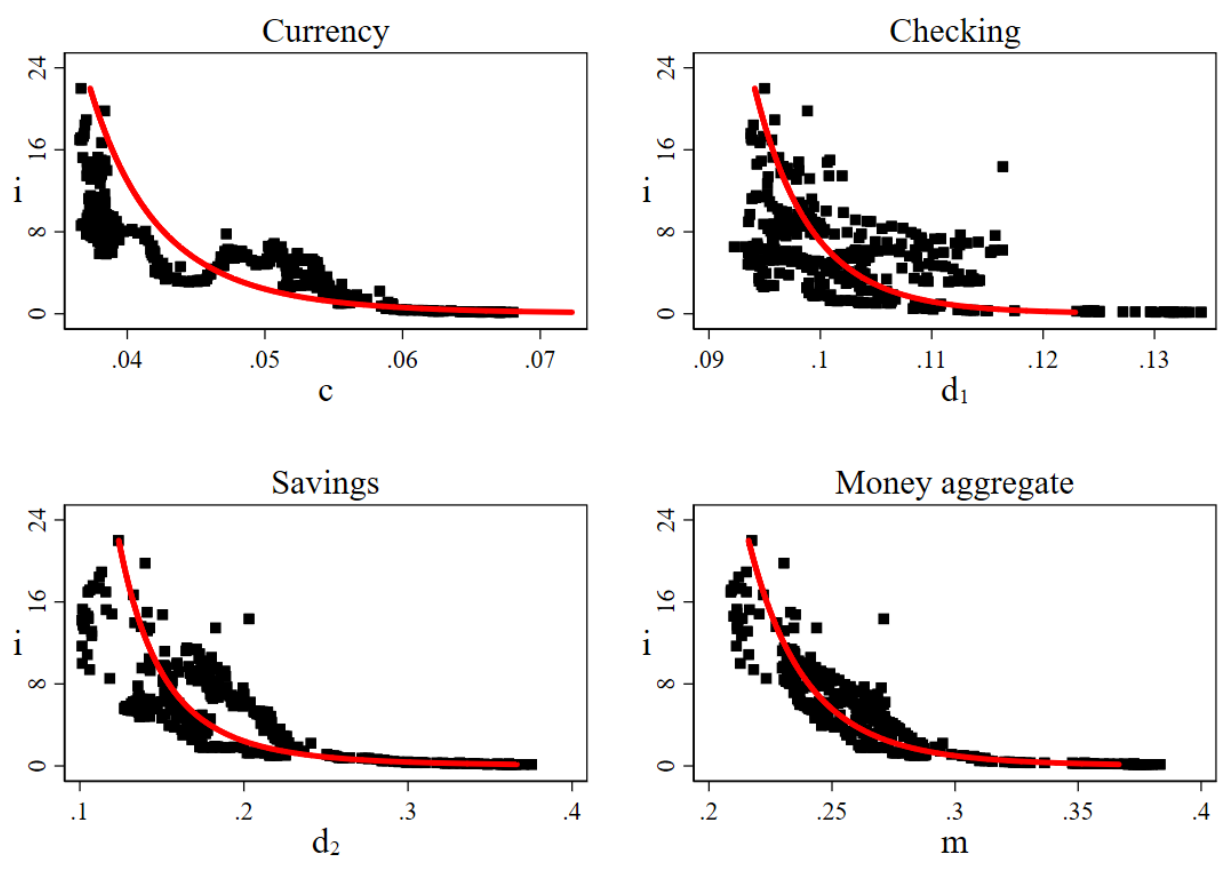

Figure 3: Money demand

$s_{k t}$ be the composite deposit spread in county $k$ in period $t$, constructed by aggregating the spreads on different types of deposits using (7). I estimate:

$$
\log d_{k t}=a_{0}-\eta_{d} \log s_{k t}+v_{k t}
$$

There are several difficulties in estimating $\eta_{d}$. The first is that for many county-year observations, especially when interest rates are low, measured spreads are negative, which is incompatible with the log-log specification (40). ${ }^{11} \mathrm{I}$ attempt to sidestep this difficulty by only estimating (40) on those time periods where less than 100 (out of 2668) counties have negative spreads. ${ }^{12}$ Within these time periods, I replace any observation with a negative spread with a spread equal to one basis point (truncating at 10 basis points gives almost identical results).

A second problem with estimating equation (40) by OLS is that $s_{k t}$ is likely endogenous.

within 30 miles of their home, and $75 \%$ of them within 5 miles.

${ }^{11}$ The model has no way to account for negative spreads, since households in the model would demand infinite deposits. Negative spreads could reflect banks' efforts to retain customers as part of a dynamic strategy that is not well captured by the model, or possibly fees that banks charge in addition to spreads.

${ }^{12}$ This means dropping the years 2002-2004 and 2009-2015, about half the sample. 
For instance, it's possible that banks might respond to a local increase in the demand for deposits by raising spreads, which would bias the estimate of $\eta_{d}$ towards zero. In other words, I need to make identifying assumptions to make sure that I am estimating the elasticity of demand rather than supply. I do this by using an instrumental variables strategy in the spirit of Bartik (1991). ${ }^{13}$ For each county, I compute the market shares of the 10 nationallylargest banks at the beginning of my sample. I then use these market shares, interacted with a full set of time dummies, to instrument for $\log s_{k t}$. The assumption is that deposit spreads are partly decided at the national level for idiosyncratic bank-level reasons and therefore uncorrelated with local demand shocks. Since different local markets have different exposure to different banks' pricing, this creates cross-sectional variation in spreads that is uncorrelated with $v_{k t} .{ }^{14} \mathrm{I}$ include county fixed effects in the regression, so I am only exploiting within-county variation in spreads driven by changes over time in national banks' deposit pricing policies.

A third problem with this estimation is that the deposit quantity data, which is taken from the FDIC, is a simple sum rather than an aggregate constructed according to (4). Furthermore, it includes all deposit types, including time deposits, which are not part of composite deposits when I set $J=2$. This introduces measurement error in $d_{k t}$. If the measurement error is correlated with the instrument, this biases the estimate of $\eta_{d}$. For instance, suppose national banks that operate in county $k$ raise savings-deposit spreads for idiosyncratic reasons and households respond by respond by reducing savings deposits but increasing time deposits. Measured deposits will not fall even though the model-relevant quantity of deposits does. This will bias the measured $\eta_{d}$ towards zero. The available quantity data, which does not distinguish by deposit type, does not make it possible to overcome this possible bias.

The results are shown on Table 3 . The estimated elasticity is $\eta_{d}=0.20$.

Using equations (35) and (36), together with $\eta=0.11, \eta_{d}=0.20, \gamma=0.76$ and $\frac{c}{d}=0.22$, I obtain parameter values $\epsilon=0.53$ and $\alpha=0.20$.

Finally, I need to estimate $\frac{\partial \log s}{\partial \log N}$. To do this, I first compute Herfindahl concentration indices $H_{k t}$ for each county and time period. I then estimate the following specification,

\footnotetext{
${ }^{13}$ See Goldsmith-Pinkham et al. (2018) for a recent discussion of this approach

${ }^{14}$ One worry may be that individual banks may change spreads and other characteristics of the deposit service (such as the perceived solvency of the bank) at the same time. The measured elasticity would be the response to the sum of these changes. Egan et al. (2017) estimate a model where this type of effect is present.
} 


\begin{tabular}{lcc}
\hline \hline & \multicolumn{2}{c}{$\log d_{h t}$} \\
\cline { 2 - 3 } & $(1)$ & $(2)$ \\
& OLS & IV \\
\hline Log $s_{h t}$ & -0.098 & -0.200 \\
& $(0.009)$ & $(0.004)$ \\
\hline Observations & 18,732 & 18,732 \\
\hline \hline
\end{tabular}

Annual data for years 1999, 2000, 2001, 2005, 2006, 2007, 2008,

2016 and 2017 for 2,668 counties. Standard errors in parentheses

Table 3: Demand for deposits

separately for each deposit type: ${ }^{15}$

$$
s_{j k t}=\left(a_{j k}+b_{j} \log H_{k t}\right) i_{t}+v_{j k t}
$$

where $s_{j k t}$ is the spread on deposit type $j$ in county $k$ in period $t$ and $a_{j k}$ is a vector of county fixed effects. (41) imposes the linearity of spreads in $i$ implied by the model but lets the slope vary by county and over time within a county if that county's Herfindahl index changes. I then obtain $\frac{d \log s}{d \log N}$ as follows:

$$
\begin{aligned}
\frac{d \log s}{d \log N} & =-\frac{1}{s} \frac{d s}{d \log H} \\
& =-\left(\sum_{j=1}^{J} \alpha_{j} s_{j}^{1-\epsilon_{d}}\right)^{-1}\left(\sum_{j=1}^{J} \alpha_{j} s_{j}^{-\epsilon_{d}} \frac{d s_{j}}{d \log H}\right) \\
& =-\frac{\sum_{j=1}^{J} \alpha_{j} \gamma_{j}^{-\epsilon_{d}} b_{j}}{\sum_{j=1}^{J} \alpha_{j} \gamma_{j}^{1-\epsilon_{d}}}
\end{aligned}
$$

The first step just uses that with symmetric banks $H=\frac{1}{N}$. The second step uses formula (7) for aggregating spreads on different deposit types. The final step uses that $s_{j}=\gamma_{j} i$ and replaces $\frac{d s_{j}}{d \log H}$ with its empirical estimate $b_{j}$.

The problem with estimating equation (41) by OLS is that $H_{k t}$ is likely endogenous. For instance, a rise in spreads for idiosyncratic county-level reasons (for instance, due to an increase in county-level deposit demand) could attract bank entry, lowering $H_{k t}$. This would bias the estimate of $b_{j}$ downwards.

To overcome this, I exploit mergers between large banks as a predictor of concentration.

\footnotetext{
${ }^{15}$ Estimating (41) instead of a specification with $\log s_{j k t}$ on the left hand side avoids having to transform the data to deal with negative measured spreads.
} 
Garmaise and Moskowitz (2006) use a related approach to measure the effect of bank mergers on local social and economic indicators. Following their criteria, I compile a list of all the bank mergers and acquisitions in which both banks had at least $\$ 1$ billion in assets in the year prior to the merger. There are a total of 654 valid mergers between 1998 and 2017, the time range for which I have RateWatch data. For each county, I compute market shares at the beginning of the sample. I then compute a fictitious time series $\tilde{H}_{k t}$ of the Herfindahl index for each county by assuming that market shares stay constant except when there are mergers; when two banks that have branches in the same county merge, I add their market shares. I then use $\log \tilde{H}_{k t}$ as an instrument for $\log H_{k t}$ in estimating (41). Since $a_{j k}$ are county fixed effects, I am only exploiting the within-county variation that comes from changes in local concentration that are the result of mergers between large banks. The results are shown on Table 4. In the IV specification, both checking and savings spreads are estimated to respond to bank concentration, with similar magnitudes. Applying formula (42) results in a measured elasticity of spreads with respect to entry of $\frac{\partial \log s}{\partial \log N}=-1.36$.

\begin{tabular}{lccccc}
\hline \hline & \multicolumn{2}{c}{$\log s_{1}$} & & \multicolumn{2}{c}{$\log s_{2}$} \\
\cline { 2 - 3 } \cline { 5 - 6 } & $(1)$ & $(2)$ & & $(3)$ & $(4)$ \\
& OLS & IV & & OLS & IV \\
\hline $\log (\mathrm{HHI})^{*} i$ & -0.029 & 1.008 & & -0.027 & 1.040 \\
& $(0.005)$ & $(0.107)$ & & $(0.007)$ & $(0.132)$ \\
\hline Observations & 40,742 & 40,742 & & 40,742 & 40,742 \\
\hline \hline
\end{tabular}

Annual data from 1999 to 2017 for 2,668 counties. Standard errors in parentheses

Table 4: Spreads and concentration

There have been previous attempts to measure the effect of concentration on deposit spreads. Also using RateWatch and FDIC data, Drechsler et al. (2017) find significant effects of concentration when estimating a first-differences specification, which regresses the change in spreads on the change in interest rates, interacted with a measure of concentration. For measuring the profit-eroding effect of entry, what matters is the effect on levels rather than first-differences (although if spreads are exactly linear functions of interest rates, the two formulations should give the same answer). In Italian data, Focarelli and Panetta (2003) find that mergers tend to raise spreads in the short run but lower them in the long run, but their focus is on comparing merged with unmerged banks rather that measuring the effect of concentration on market-wide spreads. Prager and Hannan (1998) find that mergers are associated with an increase in market-wide spreads. In an older dataset, Berger and Hannan (1989) find a positive association between concentration and savings deposit spreads. 


\subsection{Welfare measures}

Using the measured values of $\frac{\partial \log s}{\partial \log N}=-1.36, \epsilon=0.53, \eta=0.11, \alpha=0.20$ and $\eta_{d}=0.20$ in formula (29), I obtain

$$
\frac{d u}{d i} \frac{1}{m}=-0.32
$$

At a nominal interest rate of $2.5 \%$, the estimates from Table 2 indicate that $m$ is equal to $27 \%$ of GDP. Therefore the welfare cost of a one percentage point rise in inflation is:

$$
\frac{d u}{G D P}=\underbrace{\frac{d u}{d i} \frac{1}{m}}_{-0.32} \underbrace{\frac{m}{G D P}}_{0.27} \underbrace{d i}_{0.01}=0.086 \%
$$

or 8.6 basis points of GDP.

Table 5 shows how sensitive this magnitude is to various assumptions. As discussed in Section 2.2, I don't have the data that would enable me to estimate the elasticity of substitution across deposit types. The baseline figures are computed under the assumption that $\epsilon_{d}=1$ but, as shown in columns 2-4, this makes a relatively minor difference.

As discussed in Section 2.3, there are reasons to believe that the estimation of the elasticity of demand for deposits may be biased towards zero. Columns 5 and 6 show the results of re-doing the calculations assuming a demand for deposits that is more elastic than the baseline $\eta_{d}=0.20$. Higher values of $\eta_{d}$ imply a higher welfare cost of inflation. The reason can be seen from equation (24). Higher $\eta_{d}$ implies that entry responds more strongly to changes in the interest rate. A more elastic demand for deposits means that when entry lowers spreads, profits fall less because the quantity of deposits increases more. As a result, more entry is needed to restore the free entry condition, so more resources are dedicated to bank fixed costs.

Column 7 shows the effect of re-doing the whole calculation assuming $J=3$, with small time deposits as a third component of composite deposits. Spreads on time deposits are much lower than those on savings accounts but despite being cheaper for households, the quantity held is lower. The model therefore infers that they have little weight in composite deposits $\left(\alpha_{3}=0.1\right)$ and including them doesn't change the number very much.

\begin{tabular}{|c|c|c|c|c|c|c|}
\hline Baseline & $\epsilon_{d}=0.5$ & $\epsilon_{d}=2$ & $\epsilon_{d}=10$ & $\eta_{d}=0.5$ & $\eta_{d}=1$ & $J=3$ \\
\hline 8.6 & 7.5 & 9.4 & 10.1 & 10.1 & 15.4 & 10.1 \\
\hline
\end{tabular}

Table 5: Welfare costs under different assumptions (b.p. of GDP)

Table 7 compares the welfare cost that I find with those obtained by other methods. 
Perhaps the most common approach is the one by Lucas (2000) and Ireland (2009). They assume that the relevant measure of money is M1 (adjusted for retail sweeps), and that money does not pay interest. In this case, using the values for M1 from Table 2, the welfare cost of a one percentage point increase in inflation is: ${ }^{16}$

$$
\frac{d u}{G D P}=-\underbrace{\eta_{M 1}}_{0.08} \underbrace{\frac{M 1}{G D P}}_{0.16} \underbrace{d i}_{0.01}=0.012 \%
$$

Both Lucas (2000) and Ireland (2009) mention that the focus on M1 as the relevant monetary aggregate is somewhat arbitrary. An alternative, advocated by Cysne (2003), is to base the calculation on a broader monetary aggregate. If households obtain transaction services from a monetary aggregate $M$ with user cost $\iota^{M}$, then the welfare cost of inflation can be computed as follows.

$$
\begin{aligned}
\frac{d u}{G D P} & =\frac{\frac{\partial u}{\partial M} \frac{\partial M}{\partial i} d i}{G D P} \\
& =\frac{\iota^{M}}{i} \eta_{M} \frac{M}{G D P} d i
\end{aligned}
$$

where $\eta_{M} \equiv \frac{\partial M}{\partial i} \frac{i}{M}$ is the interest elasticity of demand for the aggregate $M$. The first step is just rearranging and the second step uses the household's first order condition for money demand $\frac{\partial u}{\partial M}=\iota^{M}$.

One class of broad monetary aggregates are Divisia indices such as the MSI and the CFS Divisia M2-M4 indices. These use aggregation theory to weight the amount of transaction services provided by different forms of quasi-money assets (see Anderson and Jones (2011) and Barnett et al. (2013) for details). I show figures based on the MSI but results using the CFS indices are similar. I first estimate an affine relationship between the MSI user cost and the benchmark interest rate (by definition, the user cost is the opportunity cost of holding one unit of the index). I use specification (38) to allow for possible stickiness in the interest rates paid by the underlying assets that make up the MSI. The results are shown on Table 6. They imply that the best affine approximation to the relationship between the MSI user

\footnotetext{
${ }^{16}$ Lucas (2000) estimates a log-log specification like (39) while Ireland (2009) estimates a semi-log specification $\log m_{t}=a_{0}+a_{1} i_{t}+v_{t}$. This makes a difference for computing the welfare impact of a large change in inflation (both authors focus on the welfare gain of bringing the interest rate all the way down to zero). For a local change of the type considered here, the choice of specification doesn't make much difference as long as it's a good local approximation at the point of interest. The number I find applying this approach is not the same as the actual numbers from Lucas (2000) because he estimates the money-demand elasticity on a different sample and finds a higher number.
} 
cost and the interest rate is:

$$
\iota^{M}=\underbrace{\frac{a_{0}}{1+a_{2}}}_{1.86 \%}+\underbrace{\frac{a_{1}+a_{2}}{1+a_{2}}}_{0.26} i
$$

Replacing $\eta_{M}=0.03$ and $\frac{M S I}{G D P}=0.6$ from Table 2 and $\iota^{M}=1.86 \%+0.26 \times 2.5 \%=2.5 \%$

\begin{tabular}{lc}
\hline \hline & ${\text { User Cost } \iota^{M}}^{M}$ \\
\hline Constant & 0.0133 \\
& $(0.00080)$ \\
$i_{t}$ & 0.469 \\
& $(0.019)$ \\
$i_{t-1}-\iota_{t-1}^{M}$ & -0.286 \\
& $(0.025)$ \\
\hline \hline
\end{tabular}

Monthly data from Jan 1980 to Dec 2013. Standard errors in parentheses

Table 6: User cost of the MSI index.

into formula (43) results in $\frac{d u}{G D P}=0.018 \%$.

A similar exercise can be conducted using the model-implied index $m$ instead of a Divisia index. This is simply the welfare cost of inflation from the model if the entry margin is shut down. Conceptually, the model-implied index $m$ and the MSI are similar, except that the MSI is constructed on the basis of finer categories and solely on the basis of prices and quantities, without relying on estimates of the elasticity of substitution. Nevertheless, using both aggregates yields similar numbers.

I also compute the welfare cost from the model under the assumption that fixed costs do not represent real resource costs but are fees rebated back to the household (but taking into account the spread-reducing effects of entry). This produces an even lower figure than just shutting down the entry margin.

\begin{tabular}{|c|c|c|c|c|}
\hline Baseline & Using M1 & Using the MSI & Using $m$, no bank entry & Using $m$, entry is transfer \\
\hline 8.4 & 1.2 & 1.8 & 2.3 & 1.2 \\
\hline
\end{tabular}

Table 7: Welfare costs under alternative methods (b.p. of GDP) 


\section{Conclusion}

There is very strong evidence that deposit spreads, and thus the profitability of banks, are higher when interest rates are higher. If the banking industry is characterized by free entry and high fixed costs, this implies that a permanently higher inflation rate will induce real resources to be dedicated to chasing these profits. This is a large component of the welfare cost of inflation.

\section{A International Evidence}

The correlation between market interest rates and deposit spreads is not exclusive to the US. Figure 4 shows scatterplots of deposit spreads against market interest rates in selected countries. The slope varies by country, possibly due to differences in the degree of banking competition, but in all cases the relationship is strongly positive and not too far from linear. ${ }^{17}$

\section{B Fees}

RateWatch also collects data on several types of fees charged by banks. There are 40 categories of fees associated with deposits for which there is data for 2004-2017. ${ }^{18}$ Unfortunately,

\footnotetext{
${ }^{17}$ Canada: Non-Chequable Savings Deposits $(<100 \mathrm{k} \$)$ (V122493 ) against Overnight rate (V39079). Monthly data from Apr 2009 to Nov 2018. Source: Bank of Canada. Italy: Total Deposits - households and non-financial corporations against Official Eurosystem interest rates. Monthly data from Jan 1995 to Sep 2018. Source: Bank of Italy. Sweden: On demand deposit rates against Interbank Rate for Sweden-Less than 24 hours. Monthly data from Sep 2005 to Nov 2018. Source: Riksbank. Argentina: Common savings account against Central Bank overnight rate. Monthly data from Oct 2007 to Oct 2018. Source: BCRA.

${ }^{18}$ These are: ATM/Debit Card - Out of Network Transaction; ATM/Debit Card - Replacement Card; ATM/Debit Card - Non-Customer Transaction; Commercial Service Charges - Returned Deposit Item; Commercial Service Charges - Bill Pay Monthly; Commercial Service Charges - NSF Returned Check; Commercial Service Charges - Negative Collected Balance; Corporate Checking - Account Name; Corporate Checking - FDIC Insurance Charge; Corporate Checking - Fee for Credits; Corporate Checking - Fee for Debits; Corporate Checking - Monthly Charge; Interest Checking - Can Fee be Avoided; Interest Checking - How Much to Avoid Fee; Interest Checking - How Much to Earn Interest; Interest Checking - Monthly Charge; Interest Checking - Account Name; Money Market - Can Fee be Avoided; Money Market - Excessive Withdrawal Charges; Money Market - How Much to Avoid Fee; Money Market - Monthly Charge; Money Market - Account Name; Non-Interest Checking - Can Fee be Avoided; Non-Interest Checking - How Much to Avoid Fee; Non-Interest Checking - Monthly Charge; Non-Interest Checking - Account Name; Regular Savings - How Much to Avoid Fee; Regular Savings - Monthly Charge; Regular Savings - Can Fee be Avoided; Regular Savings - Account Name; Regular Savings - Excessive Withdrawal Charges; Service Charges - Early Closure of Acct; Service Charges - Stop Payment; Service Charges - Tax Levy; Service Charges - Telephone
} 
Canada - savings deposits

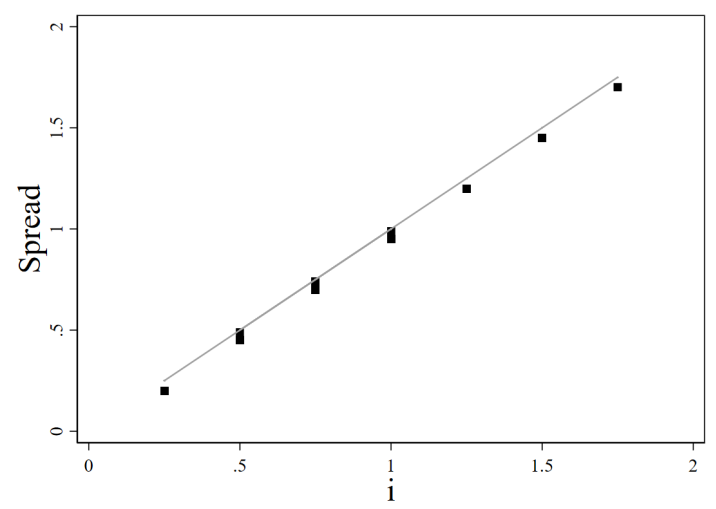

Sweden - demand deposits

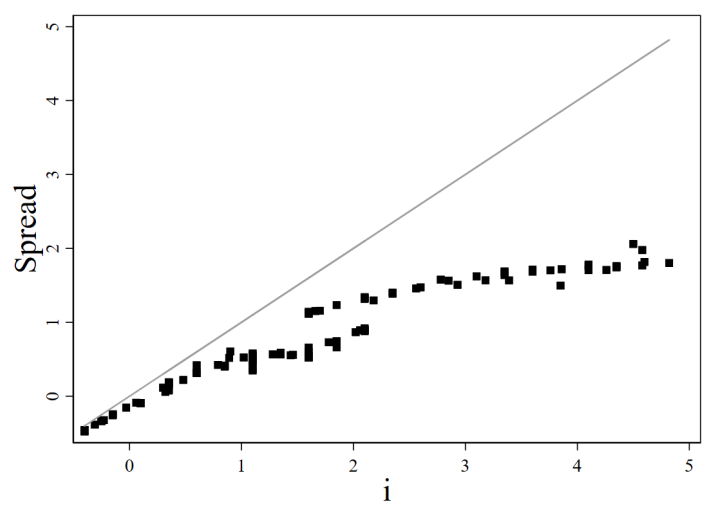

Italy - all deposits

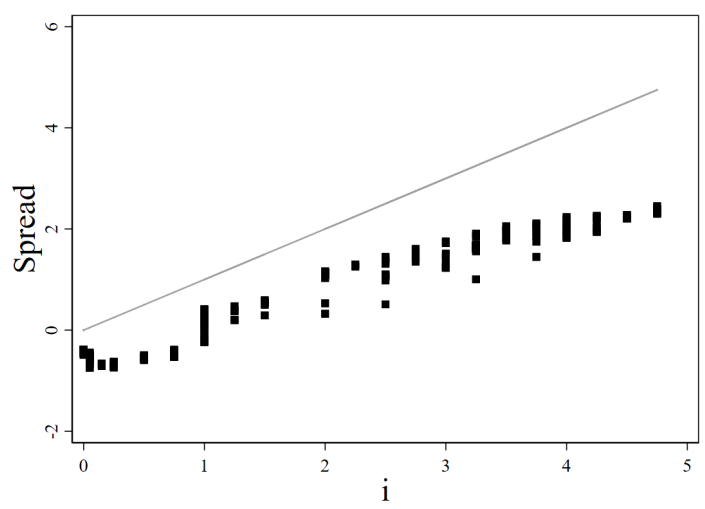

Argentina - savings deposits

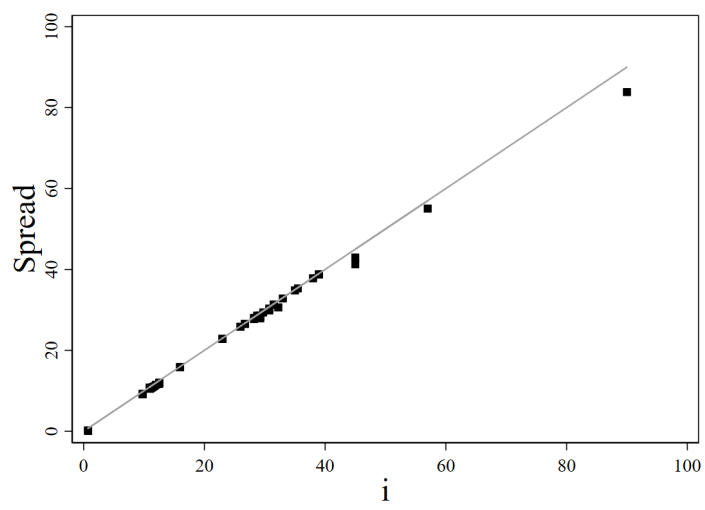

Figure 4: Spreads and interest rates in selected countries

these are quoted as absolute amounts, either per period or per event, so it's hard to convert them into percentages to make them comparable with spreads.

They do, however, co-move strongly. For each category of fee, I compute an average value across all reporting branches for each year. This results in 40 yearly time series. I standardize each of these time series and then compute principal components. The first principal component explains $49.4 \%$ of the (standardized) variation.

Figure 5 shows a scatterplot of the first principal component of fees against the nominal interest rate. Fees have a -0.46 correlation with interest rates. This means that the overall price of deposit services may respond to interest rates less strongly that what the figures on Table 1 indicate.

Transfer; Service Charges - Bill Pay Monthly; Service Charges - Dormant Account; Service Charges - Check Cash-Non-Cust; Service Charges - Statement Copy; Service Charges - Undeliverable Mail 


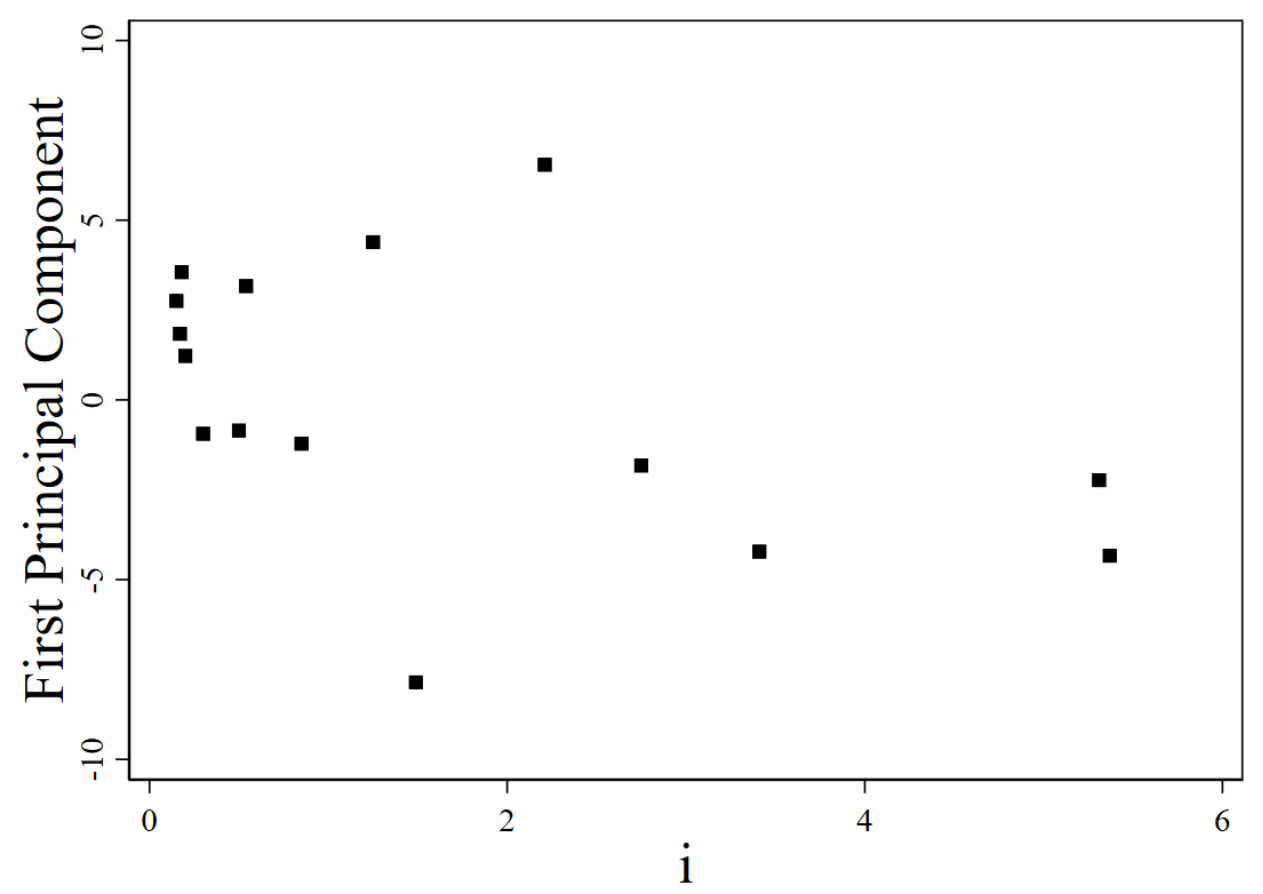

Figure 5: Fees and interest rates.

\section{References}

Aiyagari, S. R., Braun, R. A. and Eckstein, Z.: 1998, Transaction services, inflation, and welfare, Journal of political Economy 106(6), 1274-1301.

Amel, D. F., Kennickell, A. B., Moore, K. B. et al.: 2008, Banking market definition: evidence from the survey of consumer finances. FEDS Working Paper 2008-35.

Amel, D. F. and Starr-McCluer, M.: 2002, Market definition in banking: Recent evidence, The Antitrust Bulletin 47(1), 63-89.

Anderson, R. G. and Jones, B.: 2011, A comprehensive revision of the us monetary services (divisia) indexes, Federal Reserve Bank of St. Louis Review 93(September/October 2011).

Bailey, M. J.: 1956, The welfare cost of inflationary finance, Journal of Political Economy $\mathbf{6 4}(2), 93-110$.

Barnett, W. A., Liu, J., Mattson, R. S. and van den Noort, J.: 2013, The new cfs divisia monetary aggregates: Design, construction, and data sources, Open Economies Review 24(1), 101-124. 
Bartik, T. J.: 1991, Who benefits from state and local economic development policies?

Berger, A. N. and Hannan, T. H.: 1989, The price-concentration relationship in banking, The Review of Economics and Statistics pp. 291-299.

Bresciani Turroni, C.: 1937, The economics of inflation: A Study of Currency Depreciation in Post-War Germany, George Allen and Unwin, London.

Craig, B. R. and Dinger, V.: 2014, The duration of bank retail interest rates, International Journal of the Economics of Business 21(2), 191-207.

Cysne, R. P.: 2003, Divisia index, inflation, and welfare, Journal of Money, Credit and Banking 35(2), 221-238.

Di Tella, S. and Kurlat, P.: 2017, Why are banks exposed to monetary policy? Stanford University Working Paper.

Dotsey, M. and Ireland, P.: 1996, The welfare cost of inflation in general equilibrium, Journal of Monetary Economics 37(1), 29-47.

Drechsler, I., Savov, A. and Schnabl, P.: 2017, The deposits channel of monetary policy, The Quarterly Journal of Economics 132(4), 1819-1876.

Driscoll, J. C. and Judson, R.: 2013, Sticky deposit rates. FEDS Working Paper No. 2013-80.

Egan, M., Hortaçsu, A. and Matvos, G.: 2017, Deposit competition and financial fragility: Evidence from the us banking sector, American Economic Review 107(1), 169-216.

English, W. B.: 1999, Inflation and financial sector size, Journal of Monetary Economics $\mathbf{4 4}(3), 379-400$.

Focarelli, D. and Panetta, F.: 2003, Are mergers beneficial to consumers? evidence from the market for bank deposits, American Economic Review 93(4), 1152-1172.

Garmaise, M. J. and Moskowitz, T. J.: 2006, Bank mergers and crime: The real and social effects of credit market competition, the Journal of Finance 61(2), 495-538.

Goldsmith-Pinkham, P., Sorkin, I. and Swift, H.: 2018, Bartik instruments: What, when, why, and how. NBER Working Paper. 
Hannan, T. H. and Berger, A. N.: 1991, The rigidity of prices: Evidence from the banking industry, The American Economic Review 81(4), 938.

Ireland, P. N.: 2009, On the welfare cost of inflation and the recent behavior of money demand, American Economic Review 99(3), 1040-52.

Kleiman, E.: 1989, The costs of inflation. Working Paper, Hebrew University of Jerusalem.

Lucas, R. E.: 2000, Inflation and welfare, Econometrica pp. 247-274.

Marom, A.: 1998, Inflation and israel's banking industry, Bank of Israel Economic Review 62, 30-41.

Neumark, D. and Sharpe, S. A.: 1992, Market structure and the nature of price rigidity: evidence from the market for consumer deposits, The Quarterly Journal of Economics $\mathbf{1 0 7}(2), 657-680$.

Prager, R. A. and Hannan, T. H.: 1998, Do substantial horizontal mergers generate significant price effects? evidence from the banking industry, The Journal of Industrial Economics 46(4), 433-452.

Wicker, E.: 1986, Terminating hyperinflation in the dismembered habsburg monarchy, The American Economic Review 76(3), 350-364.

Yankov, V.: 2014, In search of a risk-free asset. FEDS Working Paper No. 2014-108.

Yoshino, J. A.: 1993, Money and banking regulation: The welfare costs of inflation. Ph.D. dissertation, University of Chicago. 